\title{
UMA PROPOSTA DE SÍNTESE PARA O ENSINO INTEGRADO DAS DISCIPLINAS EXPERIMENTAIS DE QUÍMICA ORGÂNICA E INORGÂNICA NOS CURSOS DE GRADUAÇÃO
}

Robson Fernandes de Farias*

Departamento de Química, Universidade Federal de Roraima, CP 167, 69301-970 Boa Vista - RR

Recebido em 6/2/02; aceito em 30/4/02

\begin{abstract}
A PROPOSAL OF SYNTHESIS FOR THE INTEGRATED TEACHING OF ORGANIC AND INORGANIC EXPERIMENTAL CHEMISTRY IN THE UNDERGRADUATE COURSES The synthesis of the layered compound $\mathrm{VO}\left(\mathrm{PO}_{4}\right)\left(\mathrm{H}_{2} \mathrm{O}\right)_{2}$ and its use to oxidize 2-butanol to the ketone 2-butanone, is proposed as an experiment to integrate the organic and inorganic experimental undergraduate chemistry courses, in an atempt to overcome the observed disrupture between organic and inorganic chemistry.
\end{abstract}

Keywords: vanadium compounds; experimental chemistry; undergraduate students.

\section{INTRODUÇÃO}

Os avanços tecnológicos observados nas últimas décadas, sobretudo nos chamados novos materiais, têm contribuído para a interpenetração experimental e teórica de diferentes ciências, ou subáreas de uma mesma ciência, num fenômeno denominado de interdisciplinaridade. No que diz respeito à química em particular, as barreiras artificialmente estabelecidas durante sua evolução ${ }^{1}$ têm sido progressivamente superadas, abrindo espaço para o ensino integrado de suas diferentes sub-áreas através, por exemplo, da ciência de materiais ${ }^{2}$. Destaque-se ainda, dentro desta perspectiva, o uso de tecnologias interativas ${ }^{3}$, a integração teoria-prática ${ }^{4}$ e a contextualização no ensino ${ }^{5}$. Nos parâmetros curriculares nacionais (PCN), os chamados temas transversais ${ }^{6}$ são propostos como forma de interrelacionar e contextualizar as diferentes disciplinas.

No ensino médio, observa-se uma nítida separação entre o ensino da química orgânica e as demais sub-áreas da química, inclusive com um livro (o vol. 3) dedicado exclusivamente à química orgânica, que geralmente é ensinada no terceiro ano. Assim estabelece-se, desde o ensino médio, a noção de que a química orgânica é uma "química diferente", à parte dos demais conteúdos que envolvem o ensino-aprendizagem da ciência química.

Nos cursos universitários, tal separação também se faz sentir, tanto nos cursos teóricos quanto nas disciplinas experimentais, parecendo que a química é dividida em compartimentos estanques, com uma total desvinculação entre a parte "orgânica" e a parte "inorgânica" da química. Tal separação, extremamente nociva, termina por se perpetuar na vida profissional dos futuros químicos observando-se, de modo geral, pouco entrosamento entre os "orgânicos" e os "inorgânicos", esquecendo-se que a química é uma só, com as subdivisões existentes determinadas por fatores históricos ligados à própria evolução da química enquanto ciência, bem como pela necessidade de subdividir o conhecimento existente, a fim de facilitar sua sistematização ${ }^{1}$. Chega-se mesmo a observar, não raras vezes, certa dose de preconceito entre os "orgânicos" e os "inorgânicos", cada um considerando a sua fração (facção?) do conhecimento químico como a mais importante.

Numa tentativa de superar já na graduação a disjunção entre “or-

*e-mail: robdefarias@yahoo.com.br gânicos" e "inorgânicos", o presente artigo traz uma proposta de prática que visa integrar os cursos experimentais de química orgânica e inorgânica. Para tal apresenta-se a síntese do composto lamelar $\mathrm{VO}\left(\mathrm{PO}_{4}\right)\left(\mathrm{H}_{2} \mathrm{O}\right)_{2}$ e sua subsequente utilização para a oxidação do 2butanol à 2-butanona.

\section{PARTE EXPERIMENTAL}

\section{Síntese do $\mathrm{VO}\left(\mathrm{PO}_{4}\right)\left(\mathrm{H}_{2} \mathrm{O}\right)_{2}$}

O composto lamelar (ver comentários) $\mathrm{VO}\left(\mathrm{PO}_{4}\right)\left(\mathrm{H}_{2} \mathrm{O}\right)_{2}$ pode ser sintetizado conforme descrito a seguir ${ }^{7}$ :

a) triture 11,0 mmols de $\mathrm{V}_{2} \mathrm{O}_{5}$, pesando em seguida 5,3 mmols deste composto;

b) coloque os 5,3 mmols de $\mathrm{V}_{2} \mathrm{O}_{5}$ num balão de fundo redondo de $50 \mathrm{~cm}^{3}$ (acrescente uma barra magnética). Adicione então 5,3 $\mathrm{cm}^{3}$ de ácido fosfórico concentrado, $11 \mathrm{~cm}^{3}$ de água e três gotas de ácido nítrico concentrado;

c) deixe a mistura preparada anteriormente em refluxo por $3 \mathrm{~h}$;

d) espere a mistura esfriar e então filtre os cristais formados, lavando-os com $20 \mathrm{~cm}^{3}$ de água e $10 \mathrm{~cm}^{3}$ de acetona (nesta ordem). Aguarde até o composto secar à temperatura ambiente.

\section{Utilização do $\mathrm{VO}\left(\mathrm{PO}_{4}\right)\left(\mathrm{H}_{2} \mathrm{O}\right)$, para a obtenção da 2-butanona a partir do 2-butanol}

Compostos de vanádio (V) são fortes oxidantes. Nesta etapa da prática, o composto $\mathrm{VO}\left(\mathrm{PO}_{4}\right)\left(\mathrm{H}_{2} \mathrm{O}\right)_{2}$, será utilizado para oxidar o 2butanol a 2-butanona, de acordo com a reação ${ }^{8}$ :

$2 \mathrm{VO}\left(\mathrm{PO}_{4}\right)\left(\mathrm{H}_{2} \mathrm{O}\right)_{2}+\mathrm{CH}_{3} \mathrm{CH}_{2} \mathrm{CH}(\mathrm{OH}) \mathrm{CH}_{3} \rightarrow$

$2 \mathrm{VO}\left(\mathrm{HPO}_{4}\right)\left(\mathrm{H}_{2} \mathrm{O}\right)_{0,5}+\mathrm{CH}_{3} \mathrm{CH}_{2} \mathrm{COCH}_{3}+3 \mathrm{H}_{2} \mathrm{O}$

Seguindo-se o seguinte procedimento experimental:

1) coloque $2,53 \mathrm{mmols}$ de $\mathrm{VO}\left(\mathrm{PO}_{4}\right)\left(\mathrm{H}_{2} \mathrm{O}\right)_{2}$ e $10 \mathrm{~cm}^{3}$ de 2-butanol em um balão de fundo redondo de $25 \mathrm{~cm}^{3}$ (utilize uma barra magnética para agitação). Aqueça a mistura até a temperatura de refluxo, deixando-a refluxar por $24 \mathrm{~h}$;

2) deixe a mistura resultante esfriar e então filtre os cristais azuis, ou seja o composto $\mathrm{VO}\left(\mathrm{HPO}_{4}\right)\left(\mathrm{H}_{2} \mathrm{O}\right)_{0,5}$. A presença de 2-butanona no filtrado pode ser testada utilizando-se 2,4,-dinitrofenilhidrazina 9 


\section{COMENTÁRIOS E SUGESTÕES}

Caberá a cada professor, de acordo com sua realidade específica, decidir qual a melhor forma de aproveitamento do experimento proposto. Pretende-se que o experimento seja "deixado em aberto", permitindo-se a cada professor as adaptações necessárias. Contudo, alguns comentários e sugestões relativos ao experimento em si, ou ao seu aproveitamento num curso integrado de química orgânica/química inorgânica, talvez possam ser úteis:

1) Neste experimento, exemplifica-se a utilização de um composto inorgânico para a preparação de um composto orgânico (o composto de vanádio $(\mathrm{V})$ neste caso, não se enquadra na definição estrita de catalisador, uma vez que sua composição química é alterada após a reação), respondendo-se à tão corriqueira (e irritante para alguns professores) pergunta, insistentemente formulada pelos estudantes: para que serve este composto que preparamos?

2) A prática proposta tanto pode ser realizada num curso de química experimental inorgânica quanto num de química orgânica, devendo o professor, em qualquer dos casos, ressaltar a sobreposição das químicas orgânica e inorgânica no experimento. Pode-se ainda promover uma total interação/integração dos cursos experimentais de química orgânica e inorgânica: os "inorgânicos" sintetizariam o composto $\mathrm{VO}\left(\mathrm{PO}_{4}\right)\left(\mathrm{H}_{2} \mathrm{O}\right)_{2}$, que seria então utilizado pelos "orgânicos" para a síntese da 2-butanona a partir do 2-butanol, devolvendo-se então aos "inorgânicos", o novo composto, ou seja, o $\mathrm{VO}\left(\mathrm{HPO}_{4}\right)\left(\mathrm{H}_{2} \mathrm{O}\right)_{0.5}$. Perceba-se que a reação entre $\mathrm{VO}\left(\mathrm{PO}_{4}\right)\left(\mathrm{H}_{2} \mathrm{O}\right)_{2}$ e 2-butanol pode ser encarada sob duas perspectivas distintas: como rota de síntese para a 2-butanona (diriam os orgânicos), ou como rota de síntese para o $\mathrm{VO}\left(\mathrm{HPO}_{4}\right)\left(\mathrm{H}_{2} \mathrm{O}\right)_{0,5}$ (diriam os inorgânicos).

3) Caso não se disponha de muitos recursos para a caracterização dos produtos formados, a síntese de cada composto de vanádio poderá ser confirmada simplesmente pela mudança de colora- ção, visto que o $\mathrm{V}_{2} \mathrm{O}_{5}$ é um sólido marrom, o $\mathrm{VO}\left(\mathrm{PO}_{4}\right)\left(\mathrm{H}_{2} \mathrm{O}\right)_{2}$ é amarelo e o $\mathrm{VO}\left(\mathrm{HPO}_{4}\right)\left(\mathrm{H}_{2} \mathrm{O}\right)_{0,5}$ é azul. Para confirmar a formação da 2-butanona, poder-se-á utilizar a reação desta com a 2,4,dinitrofenil-hidrazina, conforme sugerido anteriormente. Caso não se disponha deste reagente, ou de qualquer outro método analítico, uma alteração de odor apenas (comparando-se 2-butanol e 2-butanona) poderá ser utilizada como critério (Cuidado! Os compostos devem ser aspirados brevemente, evitando-se inalar grandes quantidades). Caso existam recursos disponíveis, a obtenção do difratograma de raios-X será suficiente para a identificação do $\mathrm{VO}\left(\mathrm{PO}_{4}\right)\left(\mathrm{H}_{2} \mathrm{O}\right)_{2}{ }_{2}^{5}$. A conversão de 2-butanol a 2-butanona poderá ser acompanhada por cromatografia gasosa, determinando-se inclusive a cinética do processo, mediante a análise de alíquotas retiradas em diferentes intervalos de tempo após o início da reação (neste caso haveria também uma integração com os cursos de química analítica e físico-química).

4) Itens para pesquisa: o que são, quais as reações e possíveis utilizações dos compostos lamelares?

\section{REFERÊNCIAS}

1. Ihde, A.J.; The Development of Modern Chemistry, Dover: New York, 1984.

2. Widstrand, C.G.; Nordell, K.J.; Ellis, A.B.; J. Chem. Ed. 2001, 78, 1044.

3. Ferreira, V.F.; Quim. Nova 1998, 21, 780.

4. Bieber, L.W., Quim. Nova 1999, 22, 605.

5. Lima, J. de F.L. de; Pina, M. do S.L.; Barbosa, R.M.N; Jófili, Z.M.S., Quim. Nova na Escola 2000, 11, 26.

6. Macedo, E.F. de; Quim. Nova na Escola 1998, 8, 23.

7. R'Kha, C.; Vandenboore, M.T.; Livage, J.; Prost, R.; Huard, E.; J. Solid State Chem. 1986, 63, 202.

8. Elisson, I.J.; Hutchings, G.J.; Sananes, M.T.; Volta, J.-C.; J. Chem. Soc. Chem. Commun. 1994, 1093.

9. Pavia, D.L.; Lampman, G.M.; Kriz, G.S.; Engel, R.G.; Organic Laboratory Techniques - Small-scale Approach, Saunders College Publishing: New York, 1998, p. 509. 